\title{
Communication
}

\section{Enumeration of Escherichia coli in Probiotic Products}

\author{
Camille Zimmer * and Caetano Dorea \\ Department of Civil Engineering, University of Victoria, Victoria, BC V8P 5C2, Canada; caetanodorea@uvic.ca \\ * Correspondence: camillezimmer@uvic.ca
}

Received: 9 September 2019; Accepted: 9 October 2019; Published: 11 October 2019

\begin{abstract}
Probiotic products typically take the form of oral supplements or food-based products containing microorganisms, typically bacteria. The number of bacteria present in a dose of probiotic can be several orders of magnitude lower than the label claims, and in some cases, undetectable. The objective of this study was to assess probiotic products containing Escherichia coli to verify manufacturer claims, which have not yet been independently assessed, regarding the number of viable E. coli per suggested dose. It was found that the products tested contained E. coli in numbers several orders of magnitude less than claimed, and when subjected to simulated stomach conditions, the number of viable $E$. coli was significantly reduced.
\end{abstract}

Keywords: probiotics; live biotherapeutics; Escherichia coli; viable cell counts

\section{Introduction}

Numerous commercially available probiotic products have been marketed to consumers using claims of improving digestion and general health. Probiotic products, which come in a variety of forms, including powders, pills, liquid suspensions, and food products, have seen a significant rise in recent years in the number of such products available [1].

Despite recommendations that a probiotic should contain a number of viable cells greater than $10^{6}$ to $10^{8}$ to be efficacious [2], studies enumerating viable cells present in a dose (as defined on the label, e.g., drops of liquid, pills, volume, or other unit of powder) of probiotic can be several orders of magnitude lower than manufacturer claims, and in some cases are undetectable [3-6]. Such studies have assessed common bacterial probiotics, such as Bifidobacterium, Lactobacillus, and Streptococci.

Probiotic products containing Escherichia coli have not yet been assessed to verify manufacturer claims regarding number of E. coli per dose of supplement. In randomized, controlled, double-blind clinical trials using human subjects, E. coli-based probiotics have been effective in reducing symptoms of constipation [7] and inflammatory bowel disease (IBD) [8], and were found to be equally as efficacious as the typical mesalazine treatment in preventing a relapse of ulcerative colitis (UC) [9]. However, several review articles have found conflicting results from multiple studies regarding the efficacy of E. coli probiotics in reducing symptoms compared to a placebo or standard treatment [10], with a lack of placebo-control or blinding in some studies [10,11]; these articles have noted that the mechanisms within the gut by which E. coli probiotics reduce symptoms is not completely understood [12], and a centralized and systematic approach to investigate E. coli products and their properties is lacking [11].

Although instructive, an assessment of respective E. coli products for enumeration fell outside the scope of the clinical trials and reviews described above. The objective of this study was to assess probiotic products containing E. coli, in order to verify manufacturer claims regarding the number of viable $E$. coli in those products. 


\section{Materials and Methods}

\subsection{Escherichia coli Probiotic Products}

Two brands of E. coli probiotic products were assessed for viable E. coli enumeration: Mutaflor (Pharma-Zentrale GmbH, Herdecke, Germany) and Symbioflor 2 (SymbioPharm GmbH, Herborn, Germany). Mutaflor claims to contain viable cells of a single E. coli strain called E. coli Nissle (EcN; DSM 6601) [13,14], and Symbioflor 2 claims to contain a mix of viable cells from six E. coli genotypes (DSM 17252) [10,15]. Mutaflor and Symbioflor 2 product samples from three different lot numbers were purchased; once received, samples were kept refrigerated until use. All tests were conducted before stated product expiry dates. Product characteristics are summarised in Table 1.

Table 1. Characteristics of studied E. coli probiotic products: Mutaflor and Symbioflor 2.

\begin{tabular}{|c|c|c|c|c|c|c|}
\hline $\begin{array}{l}\text { Product } \\
\text { Name }\end{array}$ & Format & Dose $^{1}$ & $\begin{array}{l}\text { Manufacturer } \\
\text { Claim of E. coli } \\
\text { Count per Dose } \\
1\end{array}$ & Lot Number & Purchase Date & Expiry Date $^{1}$ \\
\hline Mutaflor & $\begin{array}{l}\text { Powder } \\
\text { inside a } \\
\text { capsule }\end{array}$ & $\begin{array}{l}\text { minimum } 4 \\
\text { capsules per day }\end{array}$ & $\begin{array}{l}>1.0 \times 10^{11} \text { per } 4 \\
\quad \text { capsules }\end{array}$ & $\begin{array}{l}730160 \\
74170 \\
810180\end{array}$ & $\begin{array}{c}10 \text { February } 2018 \\
10 \text { February } 2018 \\
\text { 21 June } 2018\end{array}$ & $\begin{array}{l}11 \text { August } 2018 \\
11 \text { August } 2018 \\
25 \text { January } 2019\end{array}$ \\
\hline Symbioflor 2 & $\begin{array}{c}\text { Liquid } \\
\text { suspension }\end{array}$ & $1 \mathrm{~mL}$ & $1.5-4.5 \times 10^{7}$ & $\begin{array}{l}2564 \\
2582 \\
2584\end{array}$ & $\begin{array}{l}14 \text { July } 2018 \\
14 \text { July } 2018 \\
14 \text { July } 2018\end{array}$ & $\begin{array}{c}\text { November } 2018 \\
\text { June } 2019 \\
\text { August } 2019\end{array}$ \\
\hline
\end{tabular}

${ }^{1}$ As specified on product label.

\subsection{Product Testing}

The enumeration of viable E. coli in probiotic products was carried out under three test conditions. In Condition 1, quantification of E. coli in the supplements was performed after product dissolution in sterilized, buffered, quarter-strength isotonic Ringers (Oxoid Ltd., England, United Kingdom) solution, following an established framework for assessing probiotic products [2]. Whereas test Condition 1 verified viable $E$. coli counts in the products, it did not account for possible effects of acidic stomach conditions, which could affect viability counts. Condition 2 assessed E. coli enumeration after the products were to subjected to simulated acidic $(\mathrm{pH} 2.0)$ stomach conditions for $3 \mathrm{~h}$, as has been performed in similar evaluations [16,17]. Although mechanical digestion steps such as mastication and churning were not simulated, Mutaflor, being an encapsulated product, was assessed with regard to capsule integrity in simulated acidic stomach conditions (Condition 3). For both products examined, the lot number with the highest $E$. coli count resulting from Condition 1 was selected to be tested a minimum of three times under Condition 2. One Mutaflor capsule from each lot number was examined under Condition 3.

Intact Mutaflor capsules were sterilized by wiping the outside with 70\% ethanol (Commercial Alcohols, Brampton, ON, Canada) and allowed to dry before aseptically opening and carefully depositing the powder contents into approximately $100 \mathrm{~mL}$ of sterile Ringers solution, warmed to $37^{\circ} \mathrm{C}$ [2]. Symbioflor 2 bottle nozzles were sterilized with $70 \%$ ethanol and allowed to dry before transferring $1 \mathrm{~mL}$ of liquid suspension to $100 \mathrm{~mL}$ of sterile Ringers solution. Both mixtures were stirred on a magnetic stirrer on maximum speed (1800 rpm) for $15 \mathrm{~min}$ inside a $37^{\circ} \mathrm{C}$ incubator [2].

Under Condition 2, the $\mathrm{pH}$ of the Ringers suspension containing the probiotic sample was adjusted to 2.0, using a sterile $0.1 \mathrm{~N} \mathrm{HCl}$ solution (Acculute, VWR, Radnor, PA, United States), then was kept inside a $37^{\circ} \mathrm{C}$ incubator, stirring on low $(500 \mathrm{rpm}$ ) before and after the incubation period. After $3 \mathrm{~h}$, the $\mathrm{pH}$ was neutralized to $\mathrm{pH} 7.0$ using a sterile $0.1 \mathrm{~N} \mathrm{NaOH}$ solution (Bio Basic Inc., Toronto, ON, Canada) [16,17], and the entire neutralized mixture (approximately $100 \mathrm{~mL}$ ) was enumerated.

In Condition 3, Mutaflor capsules were placed in a pH-adjusted Ringers solution (as in Condition 2) for a $3 \mathrm{~h}$ test period. Capsules were visually inspected to determine if breakage occurred on the capsule 
surface. If a rupture was detected, the Ringers solution was neutralized (as in Condition 2), and E. coli was enumerated.

\subsection{Analytical Methods}

Under Condition 1, $1.0 \mathrm{~mL}$ of the suspension was withdrawn, and serial 10-fold dilutions were carried out using sterile Ringers solution. Under Condition 2, $100 \mathrm{~mL}$ of neutralized Ringers solution containing the probiotic sample was used for enumeration, without dilution. All samples were enumerated in triplicate using a Colilert Quanti-tray/2000 system, following the manufacturer's instructions [18]. $\mathrm{pH}$ was measured with a digital probe (PHC101, Hach, London, ON, Canada) and multimeter (HQ40d, Hach, London, ON, Canada). The enumeration methods used in this study include only counts of viable $E$. coli.

\subsection{Statistical Methods}

Descriptive statistics were used to characterize E. coli counts from samples, including arithmetic and geometric mean values, $95 \%$ confidence intervals (CIs) from triplicate trials. Results are graphically displayed, using $\log _{10}$-transformed data points for clarity. A value of 0.5 for the most probable number (MPN), half of the method detection limit, was used for data points representing non-detects when calculating means and $\log _{10}$ reductions involving non-detects. A one-way analysis of variance (ANOVA) was carried out to compare differences between lot numbers of each probiotic product under Condition 1. Further analysis of the variation between each individual lot number was undertaken using the post-hoc Bonferroni correction, to reduce the likelihood of a Type I error when making multiple comparisons. A Welch two-sample $t$-test was performed to compare the E. coli counts between Conditions 1 and 2. Any differences were considered significant at the $p \leq 0.05$ significance level. All statistical tests were performed using non- $\log _{10}$-transformed data, with $\mathrm{R}$ statistical software, version 3.4.3.

\section{Results}

Under Condition 1, the contents of one capsule of Mutaflor yielded an arithmetic mean of $8.5 \log _{10}$ MPN (most probable number) of E. coli (95\% CI 8.4-8.6), and a geometric mean of $8.1 \log _{10}$ MPN E. coli (95\% CI 7.5-8.7). The expected arithmetic mean of four capsules together (one dose, as specified on the label) is $9.1 \log _{10}$ MPN E. coli (95\% CI 9.0-9.2), and the geometric mean per dose is $8.7 \log _{10}$ MPN E. coli (95\% CI 8.1-9.3). The contents of the $1 \mathrm{~mL}$ recommended dose of Symbioflor 2 yielded an arithmetic mean of $5.0 \log _{10}$ MPN E. coli (95\% CI 4.6-5.2), and the geometric mean is $4.8 \log _{10}$ MPN E. coli $(95 \%$ CI 4.6-4.9). A comparison of products with their respective product labels is shown in Figure 1. E. coli numbers in both products were approximately 2 orders of magnitude under the label claims.

Under Condition 2, one capsule from the highest-count Mutaflor probiotic sample yielded an arithmetic mean of $2.1 \log _{10}$ MPN E. coli $(95 \% \mathrm{CI}<1-2.4)$, and a geometric mean of $0.61 \log _{10}$ MPN E. coli $(95 \% \mathrm{CI}<1-1.7)$. The expected arithmetic mean of four capsules together (one dose, as specified on the label) is $2.7 \log _{10}$ MPN E. coli $(95 \% \mathrm{CI}<1-3.2)$, and a geometric mean per dose of $1.2 \log _{10}$ MPN E. coli $(95 \% \mathrm{CI}<1-2.3)$. The contents of the $1 \mathrm{~mL}$ recommended dose of the highest-count Symbioflor 2 probiotic sample yielded an E. coli count below the method detection limit, indicating that the E. coli in Symbioflor 2 likely do not survive the acidic conditions as tested. The counts under Conditions 1 and 2 were statistically significant for both Mutaflor and Symbioflor 2, yielding $p$-values of $<0.01$.

An ANOVA revealed significant differences in E. coli counts between lot numbers of Mutaflor $(p<0.01)$, but not Symbioflor 2 samples $(p=0.06)$, enumerated under Condition 1 (Table 2). A post-hoc Bonferroni analysis of the variation between Mutaflor ${ }^{\circledR}$ lot numbers showed that the $E$. coli counts in lot numbers 740170 and 810180 were significantly different from each other $(p<0.01)$, by a mean difference of $0.67 \log _{10}$, while the remaining lot numbers tested were not significantly different from each other. 


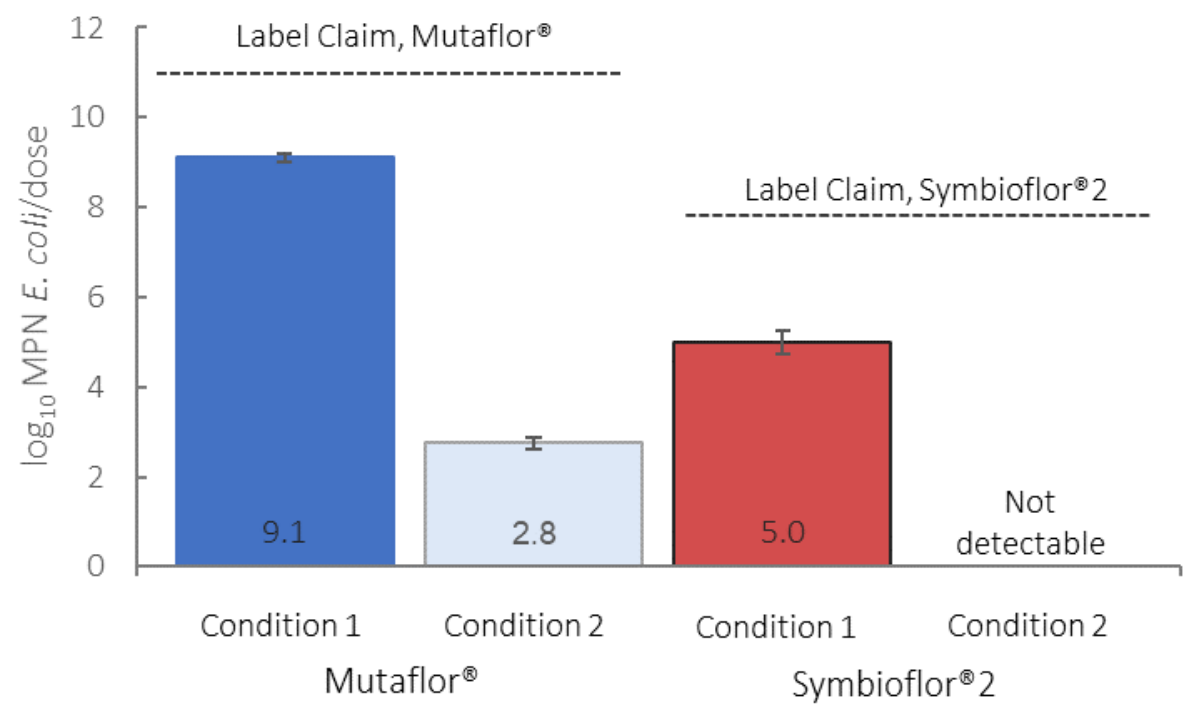

Figure 1. Comparison of $\log _{10}$-transformed arithmetic mean E. coli counts to manufacturer claims under Conditions 1 and 2; error bars denote a 95\% confidence interval (CI).

Table 2. Results of ANOVA between the enumeration of lot numbers of Mutaflor and Symbioflor 2 under test Condition 1.

\begin{tabular}{ccc}
\hline Product Name & Total Degrees of Freedom & $p$-Value \\
\hline Mutaflor & 28 & $<0.01^{1}$ \\
Symbioflor 2 & 29 & 0.06 \\
\hline
\end{tabular}

${ }^{1}$ Significant results at the $p \leq 0.05$ confidence level.

Under Condition 3, all Mutaflor capsules tested stayed intact. Although this representation does not factor into the mechanical digestion steps, it does indicate the potential for the capsule to survive the acidic conditions of the stomach, as advertised by the manufacturer [13]. It has been noted $[1,19,20]$ that encapsulation and microencapsulation do offer protection against stomach conditions, to give probiotic bacteria a chance to reach the lower gastrointestinal (GI) tract.

\section{Discussion}

Two E. coli probiotics were assessed, and both yielded E. coli counts of approximately two orders of magnitude lower than the respective label claims. This is aligned with previous studies regarding discrepancies between the label claims of probiotics and the delivery and retention of probiotic organisms within the lower GI tract [3-6].

Although there is an established framework in the literature [2] to enumerate probiotic products, in the region of study (Canada) there is not currently oversight by the government with respect to methods of probiotic enumeration [21] to obtain label claims, and there is little transparency by manufacturers with respect to their enumeration methods. The manufacturer of Mutaflor cited a plate count method using non-selective Trypic Soy Agar, which does not select for E. coli in enumeration; to our knowledge, specific $E$. coli counts were not confirmed by the manufacturer as were examined in this study. Manufacturer methods to enumerate Symbioflor E. coli counts were not reported, despite efforts to contact the manufacturer. Due to the enumeration methods used in this study, it was only confirmed that the bacteria contained in both probiotic products were E. coli, not that the E. coli strains in the products matched any EcN (DSM 6601) or DSM 17252 reference strains. Further analysis, beyond the scope of this study, would be required to compare E. coli in the probiotics tested with a reference strain; both EcN (DSM 6601) and DSM 17252 strains are maintained at the Deutsche Sammlung von Mikroorganismen und Zellkulturen (German Collection of Microorganisms and Cell Cultures) (DSMZ; Braunschweig, Germany) [22]. 
The results above indicate that the E. coli in Symbioflor 2 likely do not survive the acidic conditions as tested, and that if the Mutaflor capsule is ruptured during digestion, and the contents exposed to a low-pH environment, the resulting arithmetic mean E. coli count is $2.1 \log _{10}$ MPN E. coli. By comparison, the mean count of viable E. coli in the lower intestine is between 3.3 and $6.2 \log _{10}$ [23]. E. coli is not among the 57 most abundant microbiological species found in a study of 124 European individuals [24], potentially limiting the impact of E. coli probiotic products on gut health, due to competition from other microbiological species for gut colonization [10].

The discrepancy between the general marketing claims of probiotics and actual delivery and retention of bacteria to the lower GI tract have been noted by others [1,3], expressing concerns regarding labelling following findings of erroneous identification of bacterial strains present in probiotics, as well as bacterial strains present that were not mentioned on the label $[3,25,26]$ and instability of the bacterial strains over the shelf life [27]. Further, the mechanisms within the gut by which E. coli probiotics reduce symptoms is not completely understood [12], and evidence regarding the adherence of probiotic organisms to epithelial cell walls in the lower GI tract is lacking [28]. In two studies involving human subjects, Mutaflor was given orally; after being administered for one week, EcN could only be detected in 57\% of stools one week following ingestion [29]; in another study, after being administered for 17 days, EcN could only be detected in $40 \%$ of stools two weeks following ingestion, with the number falling to $20 \%$ nine weeks following ingestion [30]. Conflicting evidence regarding the efficacy of $E$. coli probiotics to reduce symptoms in comparison to a placebo or standard treatment [10], as well as a lack of placebo control or blinding in some studies $[10,11]$, has been pointed out by systematic reviews, suggesting the lack of a centralized and systematic approach to investigate E. coli products and their properties [11].

Our study adds to the body of studies finding the number of viable strains present in a dose of a given probiotic to be several orders of magnitude lower than label claims, or undetectable [3-6]. These findings should be used when interpreting the outcomes of trials using such probiotic products. Due to such concerns, it has been recommended by others that consistent methodology be used for the enumeration of probiotic products [2].

Author Contributions: Conceptualization and methodology, C.Z. and C.D.; laboratory investigation, C.Z.; data analysis, C.Z.; writing-original draft preparation, C.Z.; writing-review and editing, C.D.; supervision, C.D.; funding acquisition, C.D.

Funding: This study was funded through a Natural Sciences and Engineering Research Council (Canada, NSERC) Engage grant.

Acknowledgments: The authors would like to thank the technical support team in the department of civil engineering at the University of Victoria, as well as Rudolf von Bünau for his helpful input during conceptualization.

Conflicts of Interest: The authors declare no conflict of interest. The funders or product manufacturers had no role in the design of the study; in the collection, analyses, or interpretation of data; in the writing of the manuscript; or in the decision to publish the results.

\section{References and Note}

1. Caillard, R.; Lapointe, N. In vitro gastric survival of commercially available probiotic strains and oral dosage forms. Int. J. Pharm. 2017, 519, 125-127. [CrossRef] [PubMed]

2. Champagne, C.P.; Saarela, M.; Hansen, K.F.; Charalampopoulos, D. Recommendations for the viability assessment of probiotics as concentrated cultures and in food matrices. Int. J. Food Microbiol. 2011, 149, 185-193. [CrossRef] [PubMed]

3. Hamilton-Miller, J.M.T.; Shah, S.; Winkler, J.T. Public health issues arising from microbiological and labelling quality of foods and supplements containing probiotic microorganisms. Public Health Nutr. 1999, 2, $223-229$. [CrossRef] [PubMed]

4. Huff, B.A. Caveat emptor. 'Probiotics' might not be what they seem. Can. Fam. Physician 2004, 50, 583-587. [PubMed]

5. Lin, W.H.; Hwang, C.F.; Chen, L.W.; Tsen, H.Y. Viable counts, characteristic evaluation for commercial lactic acid bacteria products. Int. J. Food Microbiol. 2006, 23, 74-81. [CrossRef] [PubMed] 
6. Vinderola, C.G.; Reinheimer, J.A. Enumeration of Lactobacillus casei in the presence of L. acidophilus, bifidobacteria and lactic starter bacteria in fermented dairy products. Int. Dairy J. 2000, 10, 271-275. [CrossRef]

7. Möllenbrink, M.; Bruckschen, E. Treatment of chronic constipation with physiologic Escherichia coli bacteria. Results of a clinical study of the effectiveness and tolerance of microbiological therapy with the E. coli Nissle 1917 strain (Mutaflor). Med. Klin. (Munich) 1994, 89, 587-593. [PubMed]

8. Enck, P.; Zimmermann, K.; Menke, G.; Klosterhalfen, S. Randomized controlled treatment trial of irritable bowel syndrome with a probiotic E.-coli preparation (DSM17252) compared to placebo. Z. Gastroenterol. 2009, 47, 209-214. [CrossRef] [PubMed]

9. Kruis, W.; Schütz, E.; Fric, P.; Fixa, B.; Judmaier, G.; Stolte, M. Double-blind comparison of an oral Escherichia coli preparation and mesalazine in maintaining remission of ulcerative colitis. Aliment. Pharmacol. Ther. 1997, 11, 853-858. [CrossRef] [PubMed]

10. Wassenaar, T.M. Insights from 100 Years of Research with Probiotic E. Coli. Eur. J. Microbiol. Immunol. 2016, 6, 147-161. [CrossRef] [PubMed]

11. Beimfohr, C.A. Review of Research Conducted with Probiotic E. coli Marketed as Symbioflor. Int. J. Bacteriol. 2016, 2016, 10. [CrossRef] [PubMed]

12. Behnsen, J.; Deriu, E.; Sassone-Corsi, M.; Raffatellu, M. Probiotics: Properties, Examples, and Specific Applications. Cold Spring Harb. Perspect. Med. 2013, 3, a010074. [CrossRef] [PubMed]

13. A Bacterium Becomes a Medicinal Product. Available online: https://tinyurl.com/yywbkx9s (accessed on 17 May 2019).

14. Sonnenborn, U.; Schulze, J. The non-pathogenic Escherichia coli strain Nissle 1917-Features of a versatile probiotic. Microb. Ecol. Health Dis. 2009, 21, 122-158. [CrossRef]

15. Symbioflor@2-For Irritable Bowel Syndrome. Available online: https://tinyurl.com/yyk26qvf (accessed on 4 September 2019).

16. Brashears, M.M.; Jaroni, D.; Trimble, J. Isolation, Selection, and Characterization of Lactic Acid Bacteria for a Competitive Exclusion Product to Reduce Shedding of Escherichia coli O157:H7 in Cattle. J. Food Protect. 2003, 66, 355-363. [CrossRef] [PubMed]

17. Conway, P.L.; Gorbach, S.L.; Goldin, B.R. Survival of Lactic Acid Bacteria in the Human Stomach and Adhesion to Intestinal Cells. Int. J. Dairy Sci. 1987, 70, 1-12. [CrossRef]

18. Colilert-IDEXX, US. Available online: https://tinyurl.com/y6gyd97h (accessed on 10 July 2018).

19. Ding, W.K.; Shah, N.P. Effect of Various Encapsulating Materials on the Stability of Probiotic Bacteria. J. Food Sci. 2009, 74, 100-107. [CrossRef] [PubMed]

20. Dodoo, C.C.; Wang, J.; Basit, A.W.; Stapleton, P.; Gaisford, S. Targeted delivery of probiotics to enhance gastrointestinal stability and intestinal colonization. Int. J. Pharm. 2017, 530, 224-229. [CrossRef] [PubMed]

21. Health Canada released its guidance document on The Use of Probiotic Microorganisms in Food in April 2009.

22. German Collection of Microorganisms and Cell Cultures GmbH: Welcome to the Leibniz Institute DSMZ. Available online: https://www.dsmz.de/ (accessed on 23 September 2019).

23. Hill, M.J.; Drasar, B.S. The normal colonic bacterial flora. Gut 1975, 16, 318-323. [CrossRef] [PubMed]

24. Qin, J.; Li, R.; Raes, J.; Arumugam, M.; Burgdorf, K.S.; Manichanh, C.; Nielsen, T.; Pons, N.; Levenez, F.; Yamada, T.; et al. A human gut microbial gene catalogue established by metagenomic sequencing. Nature 2010, 464, 59-65. [CrossRef]

25. Canganella, F.; Paganini, S.; Ovidi, M.; Vettraino, A.M.; Bevilacqua, L.; Massa, S.; Trovatelli, L.D. A microbiological investigation on probiotic pharmaceutical products used for human health. Microbiol. Res. 1997, 152, 171-179. [CrossRef]

26. Temmerman, R.; Pot, B.; Huys, G.; Swings, J. Identification and antibiotic susceptibility of bacterial isolates from probiotic products. Int. J. Food Microbiol. 2003, 81, 1-10. [CrossRef]

27. Reuter, G. Present and Future of Probiotics in Germany and in Central Europe. Biosci. Microflora 1997, 16, 43-51. [CrossRef]

28. Holzapfel, W.H.; Haberer, P.; Snel, J.; Schillinger, U.; Huis in't Veld, J.H.J. Overview of gut flora and probiotics. Int. J. Food Microbiol. 1998, 41, 85-101. [CrossRef] 
29. Prilassnig, M.; Wenisch, C.; Daxboeck, F.; Feierl, G. Are probiotics detectable in human feces after oral uptake by healthy volunteers? Wien. Klin. Wochenschr. 2007, 119, 456-462. [CrossRef] [PubMed]

30. Joeres-Nguyen-Xuan, T.H.; Boehm, S.K.; Joeres, L.; Schulze, J.; Kruis, W. Survival of the probiotic Escherichia coli Nissle $1917(\mathrm{EcN})$ in the gastrointestinal tract given in combination with oral mesalamine to healthy volunteers. Inflamm. Bowel Dis. 2010, 16, 256-262. [CrossRef]

(C) 2019 by the authors. Licensee MDPI, Basel, Switzerland. This article is an open access article distributed under the terms and conditions of the Creative Commons Attribution (CC BY) license (http://creativecommons.org/licenses/by/4.0/). 